\title{
First molecular detection of Rickettsia africae in a tropical bont tick, Amblyomma variegatum, collected in Corsica, France
}

\author{
Vincent Cicculli $^{1} \cdot$ Xavier de Lamballerie $^{2} \cdot$ Remi Charrel $^{2} \cdot$ Alessandra Falchi $^{1}$ (D)
}

Received: 13 November 2018 / Accepted: 28 December 2018 / Published online: 17 January 2019

(c) The Author(s) 2019

\begin{abstract}
Here we report the first detection of Amblyomma variegatum, a tick species of medical and veterinary importance, and the first molecular evidence of a pathogen, Rickettsia africae, both new to Corsica (France). In August 2018, an ixodid tick with an unusual morphology was removed from the ventral part of a cow's whole skin in a slaughterhouse located in the village of Ponte-Leccia (Haute-Corse). The tick was morphologically identified as an adult male of $A$. variegatum. This result was confirmed by $16 \mathrm{~S}$ rDNA sequence analysis with a close relative being a sequence from Senegal showing $99 \%$ nucleotide identity. We tested the tick for Ehrlichia and Rickettsia. The tick was positive to Rickettsia and the corresponding sequence matched with $R$. africae. There is little or no risk of the introduction and establishment of a viable population of $A$. variegatum in Corsica by migrating birds. However, if it did, it could produce major economic losses for livestock production. Further studies and sustained surveillance are indicated, not only focusing on this species of tick and this rickettsia, but also on other microorganisms of veterinary and medical importance that might be transmitted in Corsica and other Mediterranean islands.
\end{abstract}

Keywords Amblyomma variegatum $\cdot$ Rickettsia africae $\cdot$ Cattle $\cdot$ Corsica $\cdot$ Mediteranean basin

\section{Introduction}

Amblyomma variegatum (Fabricius) (Acari: Ixodidae) is among the most important and widely distributed ticks of tropical livestock (Estrada-Pena et al. 2007). Adults can cause considerable direct losses in livestock by reducing growth and milk production and causing mortality by transmitting Ehrlichia ruminantium, the rickettsial agent that causes heartwater in ruminants (Allsopp 2015; Daubney 1930). Amblyomma variegatum adults are

Alessandra Falchi

falchi_a@univ-corse.fr

1 EA7310 BIOSCOPE, Laboratoire de Virologie, Université de Corse-Inserm, 20250 Corte, France

2 Unité des Virus Emergents (UVE), IHU Méditerranée Infection, Aix-Marseille Université, IRD 190, INSERM 1207, Marseille, France 
also associated with dermatophilosis (Walker and Lloyd 1993), and this tick is the natural vector of human pathogens including several species of Rickettsia and viruses (Jongejan and Uilenberg 2004). Amblyomma variegatum carries and transmits Rickettsia africae, the agent of African tick bite fever in humans, in Africa and the Caribbean region (Kelly et al. 1996, 2010).

Corsica is a French Mediterranean island characterized by a warm-summer Mediterranean climate with a high variability of microclimates because of its specific geographical situation (Grech-Angelini et al. 2016). Corsican livestock farming (sheep, goats, pigs, and cattle) is mainly of the extensive type thus important interactions between livestock, wildlife and human populations favour the circulation of tick-borne diseases. This first systematic survey of tick fauna on Corsican livestock reported a dominance of typical Mediterranean species (Rhipicephalus bursa and Hyalomma marginatum) (Grech-Angelini et al. 2016). The existence of established populations of tick species usually found in dry (Hyalomma scupense), or even in cool areas (Ixodes ricinus) has also been reported.

In order to extend knowledge about tick species infesting hosts (livestock) and their potential to cause zoonotic diseases of veterinary and medical importance it was decided: (i) to perform a systematic tick-survey from slaughtered animals, and (ii) to test for zoonotic pathogens commonly described depending upon the species. Here we report morphological and genetic identification of an exotic tick species for Corsica Island (France). We tested the tick for Ehrlichia and Rickettsia spp. and found molecular evidence of the presence of $R$. africae.

\section{Materials and methods}

The exotic tick was collected in the Corsican cattle slaughterhouse of Ponte-Leccia (HauteCorse) during a tick survey carried out in July-August 2018. The national cattle identification system, which uses ear tags, allowed us to trace the origin of animals and to identify farming owners.

The species was identified (i) with a binocular microscope using morphological keys (Walker et al. 2003), and (ii) by analyzing the sequence of one mitochondrial $460 \mathrm{bp}$ fragment of the 16S rDNA (Black and Piesman 1994) and the sequence of one 1200 bp nuclear fragment of the ribosomal internal transcribed spacer-2 (ITS-2) (Grech-Angelini et al. 2016) (Table 1).

DNA extraction was performed on a QIAcube HT (Qiagen) using a QIAamp cador Pathogen Mini kit according to the manufacturer's instructions. Ehrlichia DNA was detected using PCR performed with (i) tick-borne Anaplasmataceae specific primers targeting a 345-bp region of the $16 \mathrm{~S}$ rRNA and (ii) with the genus-specific primers amplifying a 590-bp region of the heat shock protein ( $g r o E L)$ gene (Dahmani et al. 2017) (Table 1). Rickettsia DNA was detected using PCR with primers amplifying a 850-bp region of the gltA gene encoding citrate synthase (Mediannikov et al. 2004) (Table 1). A negative (sterile water) and a positive control (E. minasensis ${ }^{1}$ and $R$. aeschlimannii) were included in every PCR run. PCR products of the expected size were purified and directly sequenced using an Applied Biosystem 3730XL. Sequences resulting from this study were deposited

\footnotetext{
1 A new Ehrlichia species recently found in the tick Rhipicephalus microplus in Brazil (Cabezas-Cruz et al. 2016).
} 


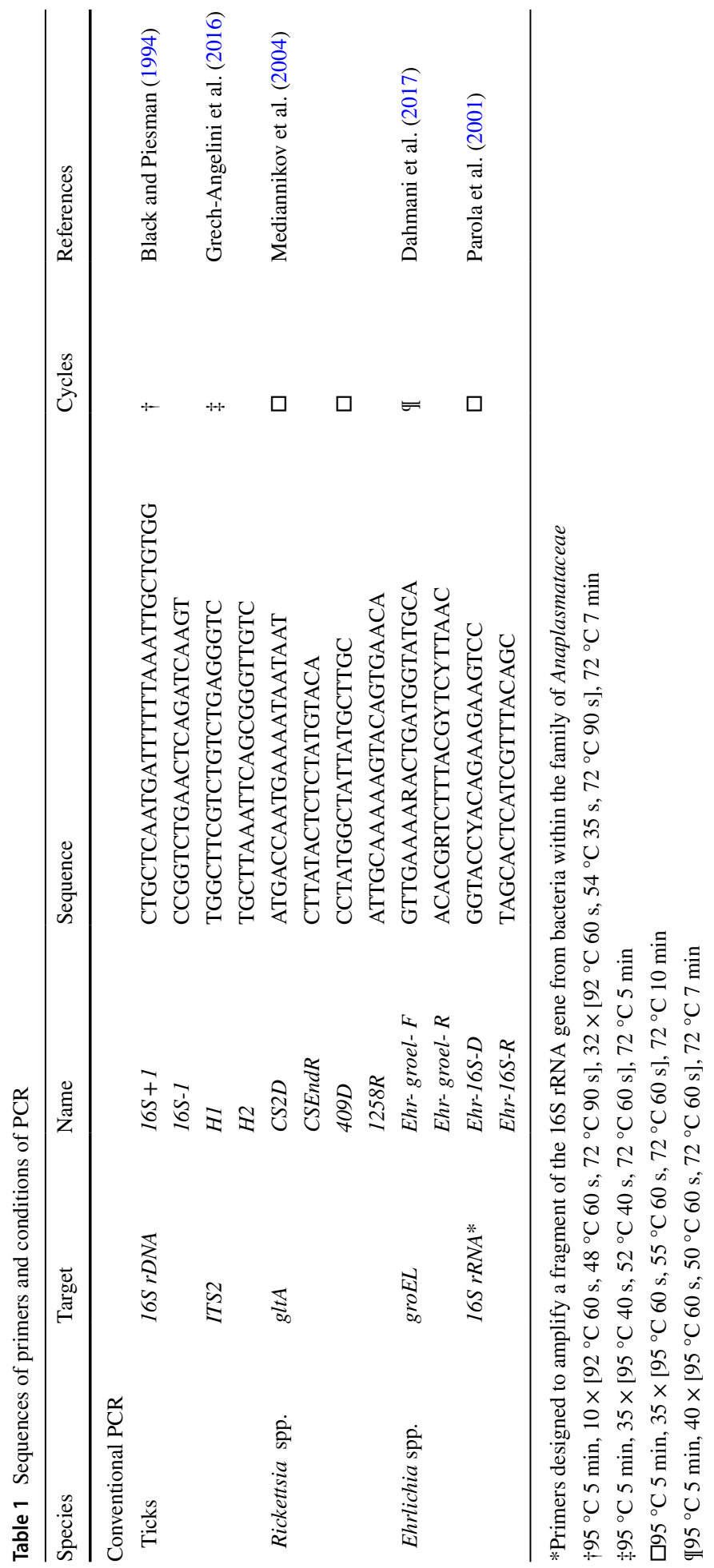



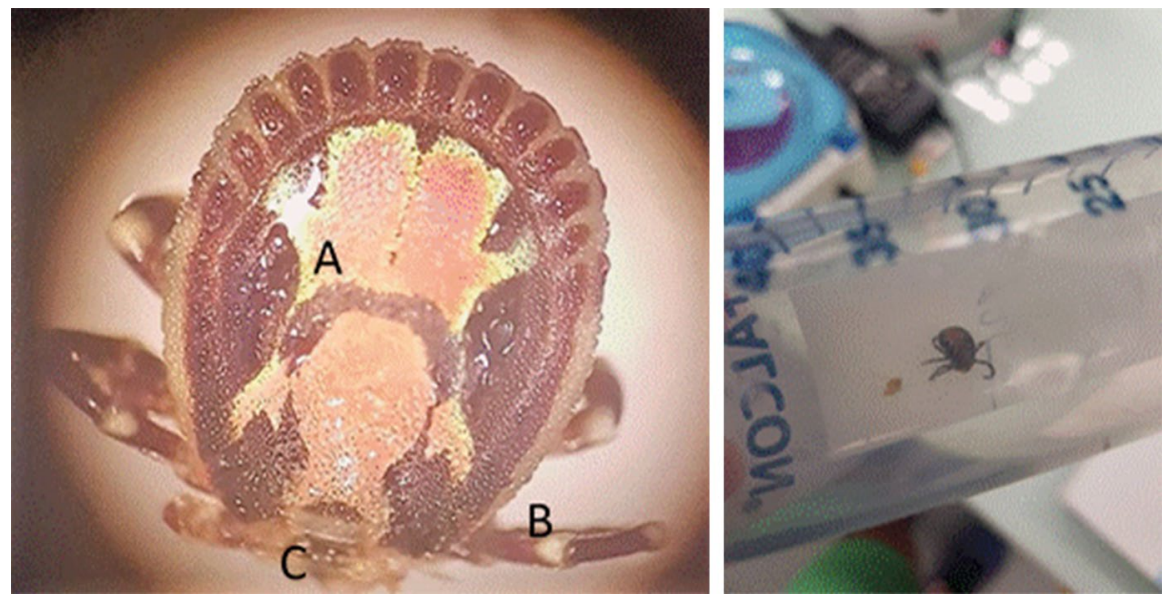

Fig. 1 Adult male tropical bont tick, Amblyomma variegatum, dorsal view. A, Medium sized punctations on the bright, yellow-gold scutum; B, banded legs; C, rostrum had been broken during removal. (Color figure online)

in GenBank accession no. for the corresponding sequences: MH843682 for 16S rDNA, MH910967 for ITS2 and MH922770 for gltA of Rickettsia. The phylogenetic analysis was performed with Maximum Likelihood method implemented on Mega X. Best fitting substitution models were determined with the Aikake Information Criterion using the ML model test implemented in Mega X (https://www.megasoftware.net/). The bootstrap consensus tree was conducted with 1000 replicates (Felsenstein 1985).

\section{Ethics statement}

No ethical approval was required, as this study does not involve clinical trials or experimental procedures. The cattle inspected were slaughtered for human consumption. The slaughterhouse staff gave permission to collect ticks from the whole skins of animals. This study did not involve endangered or protected species.

\section{Results}

Three hundred and fifty-six ticks were collected from July to August 2018 in the PonteLeccia slaughterhouse. Among the 59 inspected cows 43 (73\%) were infested. Two main tick species were morphologically identified: $R$. bursa $(\mathrm{n}=255 ; 72 \%)$ and $H$. marginatum $(\mathrm{n}=100 ; 28 \%)$.

One of the 356 ticks was morphologically identified as a male adult of $A$. variegatum (Fig. 1). The tick was manually removed from the skin of a cow (Bos taurus) on the ventral bodysurface on the 7th of August 2018. The cow had been raised in a county of northeastern Corsica.

The 16S rDNA and ITS-2 sequences confirmed the morphological identification of $A$. variegatum. The $16 \mathrm{~S}$ rDNA sequence analysis of the tick specimen showed identities (i) of 99\% with A. variegatum from Senegal (KU130401), (ii) of $98 \%$ with A. variegatum from 


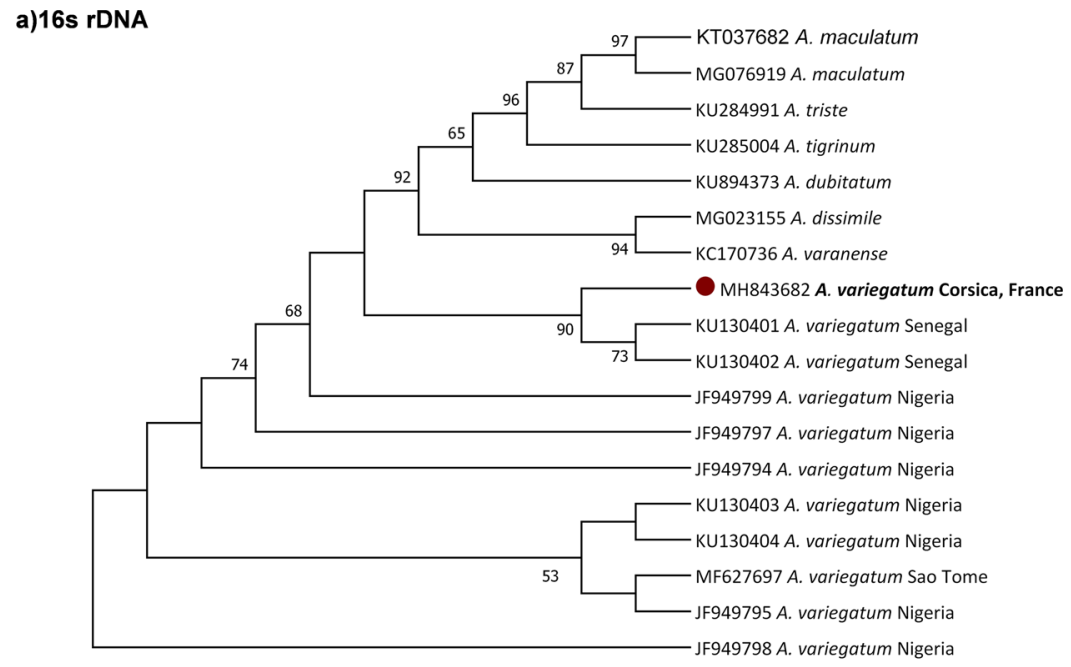

b) ITS-2

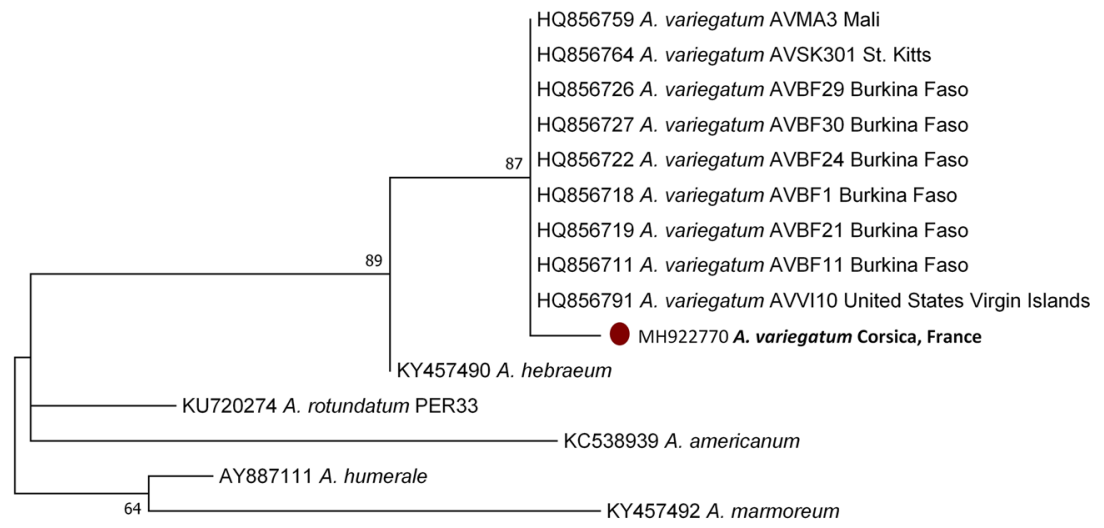

Fig. 2 Molecular phylogenetic analysis by Maximum Likelihood method of Amblyomma variegatum detected in Corsica by using 16S rDNA and ITS-2 genes. Branches corresponding to partitions reproduced in less than 50\% bootstrap replicates are collapsed. The percentage of replicate trees in which the associated taxa clustered together in the bootstrap test (1000 replicates) are shown next to the branches. a The analysis involved 18 nucleotide sequences. There were a total of 277 positions in the final dataset. b The analysis involved 15 nucleotide sequences. There were a total of 90 positions in the final dataset

Nigeria (KU130403 and JF949794) and from São Tome (MF627697), (iii) of 97\% with A. variegatum from Nigeria (JF949795, JF949797-99) (Fig. 2a). The ITS-2 sequence analysis of $A$. variegatum from Corsica was also $99 \%$ identical with A. variegatum from Burkina Faso (HQ856711, HQ856718-19, HQ856722, HQ856726-27), Mali (HQ856759), St. Kitts (HQ856764) and United States Virgin Islands (HQ856791) (Fig. 2b). This male tick was found positive for the presence of Rickettsia DNA but it was negative for the presence of Erlichia DNA. Sequence analysis of the gltA sequence obtained revealed 99 to 
$100 \%$ of identity with Rickettsia africae amplified from A. variegatum collected in Ethiopia (U59733) and in Madagascar (KJ645937-39), respectively.

\section{Discussion}

To the best of our knowledge, this report describes for the first time: (ii) the detection of $A$. variegatum in Corsica Island (France) and (ii) its positivity to $R$. africae, the most widespread spotted fever agent in sub-Saharan Africa, where it causes African tick-bite fever (Kelly et al. 1996, 2010). This tick species is widely distributed in the Caribbean Basin, in sub-Saharan Africa and in Atlantic and Indian Ocean islands. It tolerates a large climatic and environmental range from dry savannahs to more humid sylvatic regions. Sporadic occurrences of $A$. variegatum in the Mediterranean basin (Greece, Cyprus, Italy and Sicily) have been linked to the introduction by migratory birds, in particular the cattle egret, Bubulcus ibis, via transportation of larvae and nymphs (Deem 1998; Estrada-Pena et al. 2007; Pascucci et al. 2007). Interestingly, the cattle egret is present in Corsica (Thibault and Bonaccorsi 1999). The identification of the adult stage on a cow suggests the introduction of a nymph on a migrating bird from subSaharan Africa during spring migration and its moult to the adult stage during the warm summer of Corsica. There are examples of isolated reports of adults of other tropical tick genera, even in northern Europe, linked to the introduction of immatures by migratory birds from sub-Saharan Africa.

There is little or no risk of the introduction and establishment of a viable population of $A$. variegatum in Corsica by migrating birds. Isolated adults would have to meet the opposite sex in order to reproduce, and even then the species is unlikely to survive winter conditions. However, if it did (global warming!), it could produce major economic losses for livestock production through reduced growth, and perhaps most importantly by its association with severe dermatophilosis (Daubney 1930; Walker and Lloyd 1993); if infected (which is more unlikely), also by transmitting heartwater (Daubney 1930). Both are major diseases of ruminants. It could also have an impact in the medical field as one of the vectors of $R$. africae. In addition, this tick species can also transmit various viruses belonging to the Orthomyxoviridae, Reoviridae, and Bunyaviridae families, including the CrimeanCongo hemorrhagic fever virus (Jones et al. 1989; Kobayashi et al. 2017; Konstantinov 1990; Papa et al. 2017).

In Corsica, arthropod-borne pathogens were already reported such as Toscana virus in dogs (Dahmani et al. 2016) and West Nile virus in domestic animals (Maquart et al. 2017). Further studies and sustained surveillance are indicated, not only focusing on this species of tick and pathogen but also on other microorganisms of veterinary and medical importance that might be transmitted in Corsica and other Mediterranean islands.

Acknowledgements We are grateful to the staff of the slaughterhouse of Ponte-Leccia for their help in collecting ticks. This work was supported by Fonds de Recherche Collectivité de Corse.

Funding This work was supported by the Corsican Territorial Collectivity and the University of Corsica.

\section{Compliance with ethical standards}

Conflict of interest The authors declare that they have no competing interests.

Open Access This article is distributed under the terms of the Creative Commons Attribution 4.0 International License (http://creativecommons.org/licenses/by/4.0/), which permits unrestricted use, distribution, 
and reproduction in any medium, provided you give appropriate credit to the original author(s) and the source, provide a link to the Creative Commons license, and indicate if changes were made.

\section{References}

Allsopp BA (2015) Heartwater-Ehrlichia ruminantium infection. Rev Sci Tech 34:557-568

Black WCT, Piesman J (1994) Phylogeny of hard- and soft-tick taxa (Acari: Ixodida) based on mitochondrial 16S rDNA sequences. Proc Natl Acad Sci USA 91:10034-10038

Cabezas-Cruz A, Zweygarth E, Vancova M, Broniszewska M, Grubhoffer L, Passos LMF, Ribeiro MFB, Alberdi P, de la Fuente J (2016) Ehrlichia minasensis sp. nov., isolated from the tick Rhipicephalus microplus. Int J Syst Evol Microbiol 66:1426-1430. https://doi.org/10.1099/ijsem.0.000895

Dahmani M, Alwassouf S, Grech-Angelini S, Marie JL, Davoust B, Charrel RN (2016) Seroprevalence of Toscana virus in dogs from Corsica, France. Parasit Vectors 9:381. https://doi.org/10.1186/s1307 $1-016-1665-4$

Dahmani M, Davoust B, Rousseau F, Raoult D, Fenollar F, Mediannikov O (2017) Natural Anaplasmataceae infection in Rhipicephalus bursa ticks collected from sheep in the French Basque Country Ticks. Tick Borne Dis 8:18-24. https://doi.org/10.1016/j.ttbdis.2016.09.009

Daubney R (1930) Natural transmission of heartwater of sheep by Amblyomma variegatum (Fabricius, 1794). Parasitology 22:260-267

Deem SL (1998) A review of heartwater and the threat of introduction of Cowdria ruminantium and Amblyomma spp. ticks to the American mainland. J Zoo Wildl Med 29:109-113

Estrada-Pena A, Pegram RG, Barre N, Venzal JM (2007) Using invaded range data to model the climate suitability for Amblyomma variegatum (Acari: Ixodidae) in the New World. Exp Appl Acarol 41:203214. https://doi.org/10.1007/s10493-007-9050-9

Felsenstein J (1985) Confidence limits on phylogenies: an approach using the bootstrap. Evolution 39:783791. https://doi.org/10.1111/j.1558-5646.1985.tb00420.x

Grech-Angelini S, Stachurski F, Lancelot R, Boissier J, Allienne JF, Marco S, Maestrini O, Uilenberg G (2016) Ticks (Acari: Ixodidae) infesting cattle and some other domestic and wild hosts on the French Mediterranean island of Corsica. Parasit Vectors 9:582. https://doi.org/10.1186/s13071-016-1876-8

Jones LD, Davies CR, Steel GM, Nuttall PA (1989) Vector capacity of Rhipicephalus appendiculatus and Amblyomma variegatum for Thogoto and Dhori viruses. Med Vet Entomol 3:195-202

Jongejan F, Uilenberg G (2004) The global importance of ticks. Parasitology 129 (Suppl):S3-14

Kelly PJ, Beati L, Mason PR, Matthewman LA, Roux V, Raoult D (1996) Rickettsia africae sp. nov., the etiological agent of African tick bite fever. Int J Syst Bacteriol 46:611-614. https://doi.org/10.1099/00207 713-46-2-611

Kelly P, Lucas H, Beati L, Yowell C, Mahan S, Dame J (2010) Rickettsia africae in Amblyomma variegatum and domestic ruminants on eight Caribbean islands. J Parasitol 96:1086-1088. https://doi.org/10.1645/ GE-2552.1

Kobayashi D, Ohashi M, Osei JHN, Agbosu E, Opoku M, Agbekudzi A, Joannides J, Fujita R, Sasaki T, Bonney JHK, Dadzie S, Isawa H, Sawabe K, Ohta N (2017) Detection of a novel putative phlebovirus and first isolation of Dugbe virus from ticks in Accra. Ghana Ticks Tick Borne Dis 8:640-645. https:// doi.org/10.1016/j.ttbdis.2017.04.010

Konstantinov OK (1990) Ticks of the Ixodidae family as reservoir of arboviruses in the Republic of Guinea. II. Arboviruses. Rev Elev Med Vet Pays Trop 43:15-22

Maquart M, Dahmani M, Marie JL, Gravier P, Leparc-Goffart I, Davoust B (2017) First serological evidence of West Nile virus in horses and dogs from Corsica Island, France. Vector Borne Zoonotic Dis 17:275-277. https://doi.org/10.1089/vbz.2016.2024

Mediannikov OY, Sidelnikov Y, Ivanov L, Mokretsova E, Fournier PE, Tarasevich I, Raoult D (2004) Acute tick-borne rickettsiosis caused by Rickettsia heilongjiangensis in Russian Far East. Emerg Infect Dis 10:810-817. https://doi.org/10.3201/eid1005.030437

Papa A, Velo E, Kadiaj P, Tsioka K, Kontana A, Kota M, Bino S (2017) Crimean-Congo hemorrhagic fever virus in ticks collected from livestock in. Albania Infect Genet Evol 54:496-500. https://doi. org/10.1016/j.meegid.2017.08.017

Parola P, Inokuma H, Camicas JL, Brouqui P, Raoult D (2001) Detection and identification of spotted fever group Rickettsiae and Ehrlichiae in African ticks. Emerg Infect Dis 7:1014-1017. https://doi. org/10.3201/eid0706.010616

Pascucci I, Conte A, Scacchia M (2007) Use of geographic information systems to identify areas at risk of introducing Amblyomma variegatum and A. hebraeum to Italy. Vet Ital 43:655-661 
Thibault JC, Bonaccorsi G (1999) The Birds of Corsica: An annotated checklist. Herts, Tring (British Ornithologists' Union, UK)

Walker AR, Lloyd CM (1993) Experiments on the relationship between feeding of the tick Amblyomma variegatum (Acari: Ixodidae) and dermatophilosis skin disease in sheep. J Med Entomol 30:136-143

Walker A, Bouattou A, Camicas JL, Estrada-Peña A, Horak IG, Lati AA, Pegram RG, Preston PM (2003) Ticks of domestic animals in Africa: a guide to identification. Bioscience Reports, Edimburgh, Scotland, UK221 